\title{
MODELING OF STRUCTURES AND CALCULATION \\ OF IR VIBRATIONAL SPECTRA OF N,N-DIMETHYLFORMAMIDE DIMERS BY DENSITY FUNCTIONAL THEORY
}

\author{
M. B. Shundalau, ${ }^{a *}$ P. S. Chybirai, ${ }^{a}$ A. I. Komyak, ${ }^{a}$ \\ A. P. Zazhogin, ${ }^{a}$ M. A. Ksenofontov, ${ }^{b}$ and D. S. Umreiko ${ }^{b}$
}

UDC 539.19

\begin{abstract}
We present results of ab initio and DFT calculations of the structure and IR vibrational spectra of the monomer and dimers of $\mathrm{N}, \mathrm{N}$-dimethylformamide (DMF). The calculations were carried out in the B3LYP/cc-pVDZ approximation with subsequent force-field scaling. The calculated characteristics of the vibrational spectra of $D M F$ show satisfactory agreement with experimental values, allowing them to be used in spectral and structural analysis.
\end{abstract}

Keywords: ab initio calculation, density functional theory, IR spectrum, $N, N$-dimethylformamide (DMF), forcefield scaling.

Introduction. Dimethylformamide (DMF) is one of the simplest amides and has several interesting properties. DMF does not contain an NH group, which is responsible for the nature of the intermolecular structure formed by this compound in the condensed state. The methyl and aldehyde groups act as proton donors in forming dimeric and polymeric structures of DMF. Therefore, in contrast with the closest analogs of DMF, formamide (FA) and methylformamide (MFA), the molecular clusters of DMF that are formed in the liquid phase have comparatively weak binding energies and vibrational spectra that are unperturbed by the effect of strong H-bonds. Thus, DMF is a convenient subject for studying the structural and spectral characteristics of molecular systems that are important from biological and technical viewpoints. Furthermore, liquid DMF is an important aprotic dipolar solvent. DMF often fulfills the role of an organic ligand in complexes with ions and compounds of various metals owing to the presence in it of the carbonyl.

The molecular structure and vibrational spectra of DMF were studied several times both experimentally [1-9] and theoretically [7, 8, 10-12]. However, the question of whether the molecular skeleton is planar or non-planar has not yet been answered. Also, the low symmetry of the molecule is responsible for significant interactions between vibrational modes. This causes definite difficulties in assigning vibrational bands and lines. Therefore, vibrational spectra of monomeric and dimeric forms of DMF have also not been conclusively interpreted.

Herein results of quantum-chemical calculations of the structure and energy and spectral characteristics of DMF monomer and dimers are presented. Experimental IR absorption spectra are interpreted. Vibrational spectra of DMF are modeled in the gas and liquid phases.

Experimental. IR absorption spectra of DMF were recorded in the range $400-4000 \mathrm{~cm}^{-1}$ on a Bruker Vertex 70 spectrophotometer. The first sample was prepared as a solution of $\mathrm{DMF}$ in $\mathrm{CCl}_{4}(0.05 \mathrm{M})$. The second sample was pure DMF. IR spectra of the samples were recoded in a $\mathrm{KBr}$ cuvette $(0.05 \mathrm{~mm})$.

Calculations. Structural and spectral characteristics of DMF monomer and dimers were calculated using the applied quantum-chemical program GAMESS [13, 14]. The results were visualized using the MacMolPlt program [15]. The standard basis sets cc-pVDZ and cc-pVTZ [16], DFT methods, and the hybrid functional B3LYP [17-19] were utilized to optimize the equilibrium structure and calculate the force field and harmonic vibrational eigenfrequencies and intensities in IR spectra. This approach is widely used to model structures and vibrational spectra of organic com-

${ }^{*}$ To whom correspondence should be addressed.

${ }^{\mathrm{a} B e l a r u s i a n}$ State University, 4 Nezavisimosti Ave., Minsk, 220030, Belarus; e-mail: shundalov@bsu.by; ${ }^{b}$ A. N. Sevchenko Institute of Applied Physical Problems, Belarusian State University, Minsk; e-mail: lab_dozator@mail.ru. Translated from Zhurnal Prikladnoi Spektroskopii, Vol. 78, No. 3, pp. 351-361, May-June, 2011. Original article submitted January 31, 2011. 
pounds [20-22] and is highly recommended for interpreting IR and Raman spectra of methylcarbamate [23], methylphenylcarbamate [24], and 4,4'-methylenediphenyldiisocyanate (MDI) [25].

The initial force field obtained from calculations using the GAMESS program was then recalculated from $\mathrm{mdyn} / \AA \mathrm{A}$, mdyn $\cdot \stackrel{\AA}{\mathrm{A}} / \mathrm{rad}^{2}$, and mdyn/rad (for bond-bond, bond-angle, and angle-angle coupling force constants, respectively) into units of $10^{6} \mathrm{~cm}^{-2}$ using the coefficients $1.5601,1.4313$, and 1.3131 . Then, the force field was partially scaled. The resulting force field was used to calculate vibrational frequencies according to the published program [26].

Results and Discussion. Monomer structure. The structures of DMF in the gas [1, 4], liquid [4, 6, 8], and crystal [8] states were studied several times by electron-diffraction [1,6] and x-ray-diffraction [4, 8]. With the exception of the solid state, for which a planar skeleton (i.e., the bonds around the $\mathrm{N}$ atom) of monomers in the crystal structure was found [8], the experimental results $[1,4,6]$ argue in favor of a pyramidal structure for the $\mathrm{CNC}^{\prime} \mathrm{C}^{\prime \prime}$ molecular fragment. Nevertheless, several quantum-chemical ab initio and DFT calculations using various basis sets and approximations predicted $C_{s}$ point symmetry (planar skeleton) for isolated DMF [7, 10] and monomeric fragments of its dimers [11, 12]. The vibrational problem in terms of a valence-force field approximation [2, 3, 5, 7] was also solved for a planar model of the DMF skeleton. An analogous situation occurred for the determination of the equilibrium configuration of the closest DMF analogs FA and MFA, for which planar and pyramidal skeletal structure models were also examined. A non-planar form of FA was determined based on the microwave spectrum [27]. However, later investigations [28-31] were based on the assumption that the molecule was planar. Spectral [32] and electron-diffraction [33] studies of the MFA structure also invoked a planar molecular skeleton. However, data from modern microwave studies [34] were consistent with a pyramidal skeleton. The deviations of the bonds around the $\mathrm{N}$ atom from planarity were $2-3^{\circ}$ [34]. Previous ab initio and DFT calculations [34, 35] using MP2/6-31G** and B3LYP/6$31++\mathrm{G}^{* *}$ approximations predicted a practically planar skeletal configuration for both trans- and cis-MFA.

The DMF geometry was initially optimized with the assumption that the molecule had $C_{s}$ symmetry. Subsequent calculation of the Hessian demonstrated the presence of two imaginary frequencies associated with out-of-plane vibrations of the $\mathrm{N}$ atom relative to the molecular skeleton and torsional vibrations of methyls. A non-planar equilibrium skeletal configuration was obtained after relaxing the restriction on the symmetry. Calculation of the Hessian confirmed the robustness of such a configuration. The optimized equilibrium structure of DMF had the form:

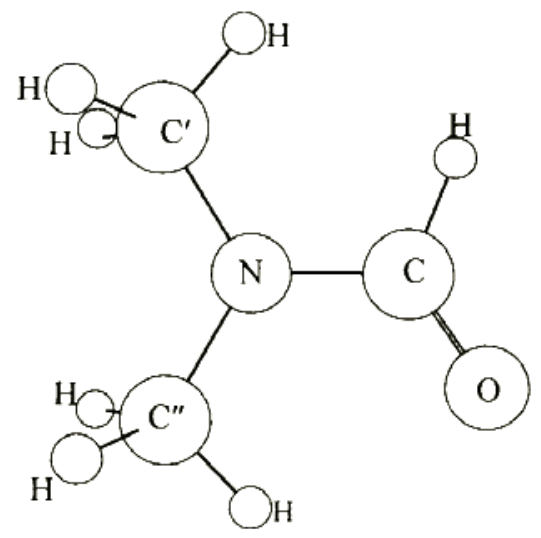

Table 1 presents the calculated structural parameters of DMF compared with the experimental electron-diffraction data for the gas phase [6]. The designations $C^{\prime}$ and $C^{\prime \prime}$ are used here and henceforth for the methyl $C$ atoms located in the trans- and cis-positions, respectively, relative to the carbonyl group. All bond lengths are given in units of Angstroms $(\AA)$; angles, in degrees $\left({ }^{\circ}\right)$. Table 1 shows that both calculations reproduced adequately the structural parameters of isolated $\mathrm{DMF}$. The deviations of the calculated $\mathrm{C}=\mathrm{O}, \mathrm{NC}^{\prime}$, and $\mathrm{NC}^{\prime \prime}$ bond lengths from the experimental values were less than $0.5 \%$; for $\mathrm{CH}$ bonds, $0.5-1.3 \%$. It is noteworthy that the experimental $\mathrm{CH}$ bond lengths [6] were averaged over all seven such bonds. The calculated length of only the $\mathrm{CN}$ bond differed from the experimental value by more (1.7\%). A similar error for the calculated $\mathrm{CN}$ bond length was also observed for MDI [25]. Apparently this is typical for the employed approximation. As a rule, the angles were reproduced with deviations of $0.5-2.0 \%$. Both calculations demonstrated that the bonds around the $\mathrm{N}$ atom deviated from the plane of the molecular skeleton. 
TABLE 1. Structural Parameters of Isolated Dimethylformamide

\begin{tabular}{|c|c|c|c|}
\hline \multirow{2}{*}{ Parameter } & \multicolumn{2}{|c|}{ Calculation } & \multirow{2}{*}{ Experiment $[6]$} \\
\hline & B3LYP/cc-pVDZ & B3LYP/cc-pVTZ & \\
\hline $\mathrm{C}=\mathrm{O}$ & 1.218 & 1.214 & $1.224 \pm 0.003$ \\
\hline $\mathrm{CN}$ & 1.368 & 1.360 & $1.391 \pm 0.007$ \\
\hline $\mathrm{NC}^{\prime}$ & 1.447 & 1.447 & $1452+0$ \\
\hline $\mathrm{NC}^{\prime \prime}$ & 1.452 & 1.452 & $1.453 \pm 0.004$ \\
\hline $\mathrm{CH}$ & 1.118 & 1.105 & \\
\hline $\mathrm{C}^{\prime} \mathrm{H}$ & $1.105,1.106,1.100$ & $1.093,1.095,1.089$ & $1.112 \pm 0.003$ \\
\hline $\mathrm{C}^{\prime \prime} \mathrm{H}$ & $1.105,1.104,1.097$ & $1.094,1.092,1.086$ & \\
\hline $\mathrm{NC}=\mathrm{O}$ & 125.7 & 125.9 & $123.5 \pm 0.6$ \\
\hline $\mathrm{NCH}$ & 111.6 & 112.0 & $117.0 \pm 2.8$ \\
\hline $\mathrm{NC}^{\prime} \mathrm{H}$ & $111.2,111.5,109.3$ & $111.0,111.4,109.3$ & $1101+02$ \\
\hline $\mathrm{NC}^{\prime \prime} \mathrm{H}$ & $111.1,110.7,107.7$ & $111.0,110.4,108.0$ & $110.1 \pm 0.3$ \\
\hline $\mathrm{C}^{\prime} \mathrm{NC}^{\prime \prime}$ & 118.5 & 118.3 & $113.9 \pm 0.5$ \\
\hline $\mathrm{CNC}^{\prime}$ & 121.6 & 121.5 & $122.3 \pm 0.4$ \\
\hline $\mathrm{CNC}^{\prime \prime}$ & 119.8 & 120.0 & $120.8 \pm 0.3$ \\
\hline $\mathrm{C}^{\prime} \mathrm{NC}=\mathrm{O}$ & 177.1 & 175.8 & $168.6 \pm 3.9$ \\
\hline $\mathrm{C}^{\prime \prime} \mathrm{NC}=\mathrm{O}$ & 1.2 & 1.5 & $16.3 \pm 4.5$ \\
\hline
\end{tabular}

Dimer structures. Dimeric and polymeric DMF structures in the liquid and crystalline states were also studied before $[4,8,11,12]$. An x-ray structure analysis (XSA) [4] indicated that liquid DMF did not exhibit bonds with lengths $>3 \AA$. This placed limitations on the extent of intermolecular bonds in DMF clusters in this aggregate state. An XSA of crystalline DMF [8] demonstrated that the crystal structure contained dimeric clusters bonded through only one H-bond $(\mathrm{C}=\mathrm{O}$...HC) of length $3.294 \AA$. Four types of DMF dimers, two of which were bonded through double H-bonds and two, through quadruple bonds, were examined using quantum-chemical calculations [11, 12]. The lengths of the H-bonds of these structures varied in the range 2.36-2.87 $\mathrm{A}$.

The structures of the DMF dimers were calculated using the B3LYP/cc-pVDZ approximation. Five stable dimeric DMF clusters were found. The Hessians of these were positively determined:

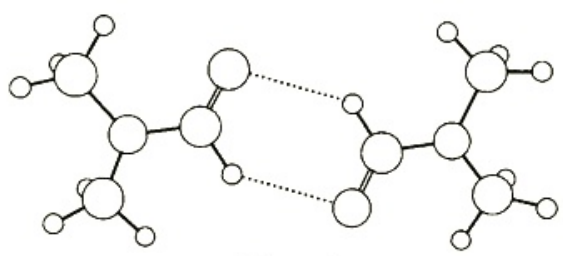

Dimer 1

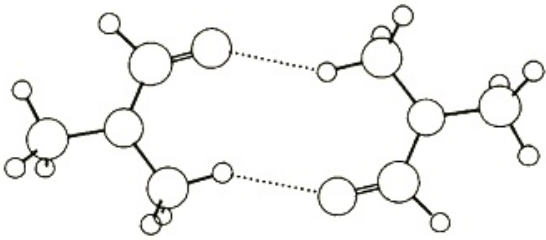

Dimer 3

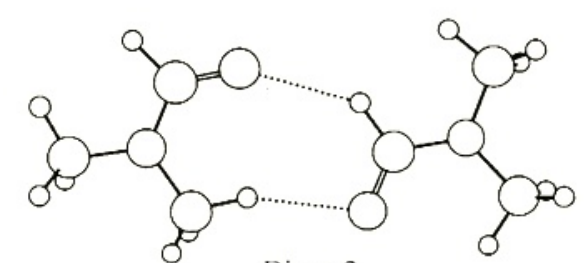

Dimer 2

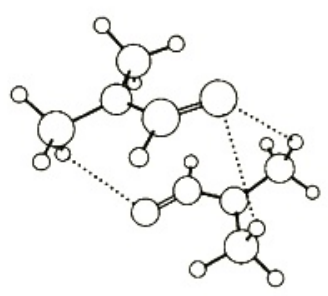

Dimer 4

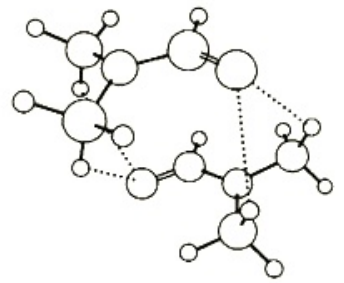

Dimer 5 
TABLE 2. Calculated Energy Characteristics of Dimethylformamide Dimers

\begin{tabular}{|c|c|c|c|c|c|}
\hline Dimer & $\begin{array}{l}\text { Relative dimer } \\
\text { energy, } \mathrm{kJ} / \mathrm{mol}\end{array}$ & $\begin{array}{l}\text { Relative dimer weight, } \\
e^{-\Delta E_{i} / k T} / \sum_{i=1}^{5} e^{-\Delta E_{i} / k T}\end{array}$ & $\begin{array}{c}\text { Binding energy } \\
\text { with BSSE, } \mathrm{kJ} / \mathrm{mol}\end{array}$ & H-bond length, $\AA$ & $\begin{array}{c}\text { Average } \mathrm{H} \text {-bond } \\
\text { energy, } \mathrm{kJ} / \mathrm{mol}\end{array}$ \\
\hline 1 & 0.00 & 0.528 & -12.20 & $\begin{array}{l}2.358(\mathrm{O} . . . \mathrm{HC}) \\
2.359(\mathrm{O} . . \mathrm{HC})\end{array}$ & 6.10 \\
\hline 2 & 2.94 & 0.161 & -12.31 & $\begin{array}{c}2.356(\mathrm{O} \ldots \mathrm{HC}) \\
2.266\left(\mathrm{O} \ldots \mathrm{HC}^{\prime \prime}\right)\end{array}$ & 6.16 \\
\hline 3 & 5.85 & 0.050 & -8.63 & $\begin{array}{l}2.279\left(\mathrm{O} . . . \mathrm{HC}^{\prime \prime}\right) \\
2.296\left(\mathrm{O} . . \mathrm{HC}^{\prime \prime}\right)\end{array}$ & 4.31 \\
\hline 4 & 6.06 & 0.046 & -8.54 & $\begin{array}{l}2.632\left(\mathrm{O} \ldots \mathrm{HC}^{\prime}\right) \\
2.699\left(\mathrm{O} \ldots \mathrm{HC}^{\prime}\right) \\
2.791\left(\mathrm{O} \ldots \mathrm{HC}^{\prime \prime}\right)\end{array}$ & 2.85 \\
\hline 5 & 2.21 & 0.216 & -9.32 & $\begin{array}{l}2.643\left(\mathrm{O} . . . \mathrm{HC}^{\prime \prime}\right) \\
2.645\left(\mathrm{O} \ldots \mathrm{HC}^{\prime \prime}\right) \\
2.701\left(\mathrm{O} . . . \mathrm{HC}^{\prime}\right) \\
2.702\left(\mathrm{O} . . . \mathrm{HC}^{\prime}\right)\end{array}$ & 2.33 \\
\hline
\end{tabular}

These clusters reflected the most probable motifs for forming intermolecular bonds in liquid DMF and were examined further as models of the DMF molecular structure in this aggregate state.

The monomeric fragments in each of the dimers are bonded through two (dimers 1,2, and 3), three (dimer 4), or four (dimer 5) H-bonds. Optimization of the geometry did not identify any dimeric cluster bonded by a single $\mathrm{H}$-bond. The most stable dimer 1 was formed through two identical $\mathrm{H}$-bonds with the aldehyde $\mathrm{H}$ atom acting as the proton donor. The energies of dimers 2 and 5 were comparable and greater. Dimer 2 was formed through two different $\mathrm{H}$-bonds of carbonyls with aldehyde and methyl $\mathrm{H}$ atoms. Dimer 5 had two pairs of H-bonds (with $\mathrm{H}$ atoms of two methyls). Dimers 3 and 4 had the greatest relative energies. Dimer 3 was formed through two identical H-bonds of carbonyls with methyl $\mathrm{H}$ atoms. The structure of dimer 4 allowed four H-bonds according to symmetry arguments. However, the length of one of them was $3.413 \AA$, which exceeded significantly the aforementioned restriction [4]. Thus, it was assumed that dimer 4 was formed through only three $\mathrm{H}$-bonds of carbonyls with methyl $\mathrm{H}$ atoms. The structures of dimers 1,3 , and 5 had approximate $C_{2}$ symmetry; dimer $4, C_{i}$.

Table 2 presents several calculated energy characteristics of the dimers. The average energies of the H-bonds fell in the range 2-6 kJ/mol. This is typical of weak H-bonds. The strongest H-bonds (with aldehyde $\mathrm{H}$ atoms) occurred in dimers 1 and 2. It is well known that the use of a limited basis set for quantum-chemical calculations produces a specific elevation of the binding energy of the molecular fragments. This effect is due to the neglect of the basis set superposition error (BSSE). The BSSE was taken into account using the standard method [36].

The structural parameters of the monomeric fragments also changed as a result of the formation of dimeric clusters. The $\mathrm{C}=\mathrm{O}$ bond length increased by 0.003 (dimer 3 ) to $0.008 \AA$ (dimers 1 and 2 ). On the other hand, the $\mathrm{CH}$ bond decreased by 0.001 (dimer 3) to $0.008 \AA$ (dimer 2). The decrease of the CN bond length ranged from 0.001 (dimer 2) to $0.009 \AA$ (dimer 5). The $\mathrm{NC}^{\prime}$ and $\mathrm{NC}^{\prime \prime}$ bond lengths changed less significantly. The former elongated by 0.003 and $0.007 \AA$ in dimers 4 and 5, remaining unchanged in the other dimers. The latter contracted by $0.001 \AA$ (dimers 1,2, and 5) and elongated by 0.003-0.004 $\AA$ (dimers 2 and 3). The $\mathrm{CH}$ bond lengths in the methyls $\left(\mathrm{C}^{\prime} \mathrm{H}_{3}\right.$ and $\mathrm{C}^{\prime \prime} \mathrm{H}_{3}$ ) and the bond angles changed insignificantly.

Thus, the analysis of the energy and structure characteristics of the dimeric models of the DMF intermolecular structure showed that monomeric fragments in the clusters were bonded through weak H-bonds with different energies. Weak H-bonds would cause small spectral shifts of absorption bands due to vibrations of atoms involved in the Hbonds (mainly carbonyls). The differences in the energies of the H-bonds would produce different spectral shifts and 


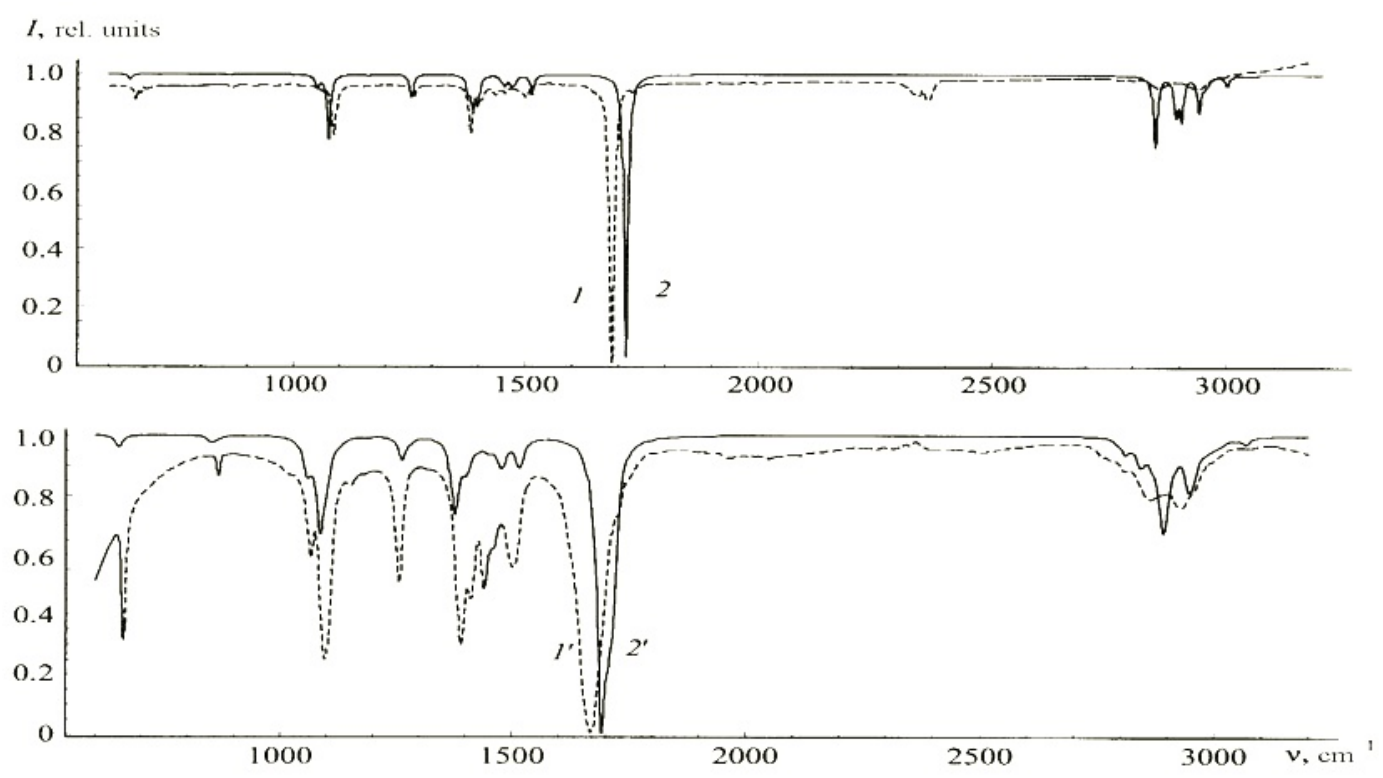

Fig. 1. IR absorption spectra of dimethylformamide: experimental $\left(\mathrm{CCl}_{4}\right.$ solution, 1; pure compound, $1^{\prime}$ ) and calculated (monomer, 2; dimers, $2^{\prime}$ ).

the appearance of several closely spaced bands in the vibrational spectrum. The intensities of these bands would be determined mainly by the relative energies (or weights, see Table 2) of the dimeric clusters.

Each of the first three dimers can exist in two isomeric forms differing in the mutual orientation of the nonplanar $\mathrm{NC}^{\prime} \mathrm{C}^{\prime \prime}$ fragments. Despite the insignificant difference in the energies of such isomers, their presence would cause additional broadening of the absorption bands.

Vibrational spectra. Figure 1 shows IR absorption spectra of a solution of DMF in $\mathrm{CCl}_{4}$ and pure DMF. Spectrum 1 was obtained by subtracting the $\mathrm{CCl}_{4}$ spectrum from the solution spectrum. Figure 2 shows portions of normalized IR spectra in the range $1580-1750 \mathrm{~cm}^{-1}$ (region of $\mathrm{C}=\mathrm{O}$ stretching vibrations). An analysis of vibrational spectra of the solution, liquid phase, and DMF vapor [3] indicated that the environment had a substantial influence on the frequency and shape of only the carbonyl absorption band. The frequencies of other vibrations shifted insignificantly.

The spectrum of DMF dissolved in $\mathrm{CCl}_{4}$ exhibited in the range $1580-1750 \mathrm{~cm}^{-1}$ two absorption bands, a strong one at $1686.2 \mathrm{~cm}^{-1}$ and a very weak one at $1730.0 \mathrm{~cm}^{-1}$. They both lacked structure and were described very well by Lorentz contours with half-widths $6.5 \mathrm{~cm}^{-1}$, centers at 1685.8 and $1730.0 \mathrm{~cm}^{-1}$, and relative intensities 1:0.02 (Fig. 2b). The band at $1686.2 \mathrm{~cm}^{-1}$ belonged obviously to the carbonyl stretching vibration shifted relative to its position at $1715 \mathrm{~cm}^{-1}$ in the vapor spectrum [3]. Such a shift may have been due to the formation of intermolecular bonds or non-bonding (van-der-Waals) interactions. In this instance, the weak band at $1730 \mathrm{~cm}^{-1}$ might be ascribed to the unshifted vibration of free $\mathrm{C}=\mathrm{O}$. However, the degree of depolarization of the line at $1728 \mathrm{~cm}^{-1}$ in the Raman spectrum of liquid DMF is 0.03 according to the literature [3]; of the line at $1676 \mathrm{~cm}^{-1}$, which corresponds to vibrations of free carbonyl, 0.20 . The last result agreed qualitatively with our calculations of the Raman spectra of the monomer and dimers. The degrees of depolarization of lines corresponding to $\mathrm{C}=\mathrm{O}$ stretching vibrations were 0.54 for the monomer and $0.67-0.74$ for the dimers. Thus, the weak band at $1730 \mathrm{~cm}^{-1}$ belonged most probably to an overtone of the symmetric stretching vibration of $\mathrm{NC}^{\prime}$ and $\mathrm{NC}^{\prime \prime}$ bonds, the principal band of which appeared as a weak band at 865 $\mathrm{cm}^{-1}$ in the spectrum of pure DMF (Fig. 1, spectrum $1^{\prime}$ ). The degree of depolarization of the corresponding line in the Raman spectrum was reported as 0.04 [3].

The band for the $\mathrm{C}=\mathrm{O}$ stretching vibration in the solution spectrum had a simple contour and was slightly broadened (Fig. 2a and b), in contrast with the spectrum of the pure liquid. The band shift was $\sim 30 \mathrm{~cm}^{-1}$ relative to its position in the vapor spectrum [3]. Keeping in mind the insignificant energies of H-bonds in dimeric DMF clusters, it seemed more probable that the shift of the carbonyl vibrational band in solution was the result of non-bonding interactions with solvent molecules. In this instance, the frequency of free $\mathrm{C}=\mathrm{O}$ vibrations in the liquid was $1686.2 \mathrm{~cm}^{-1}$. 

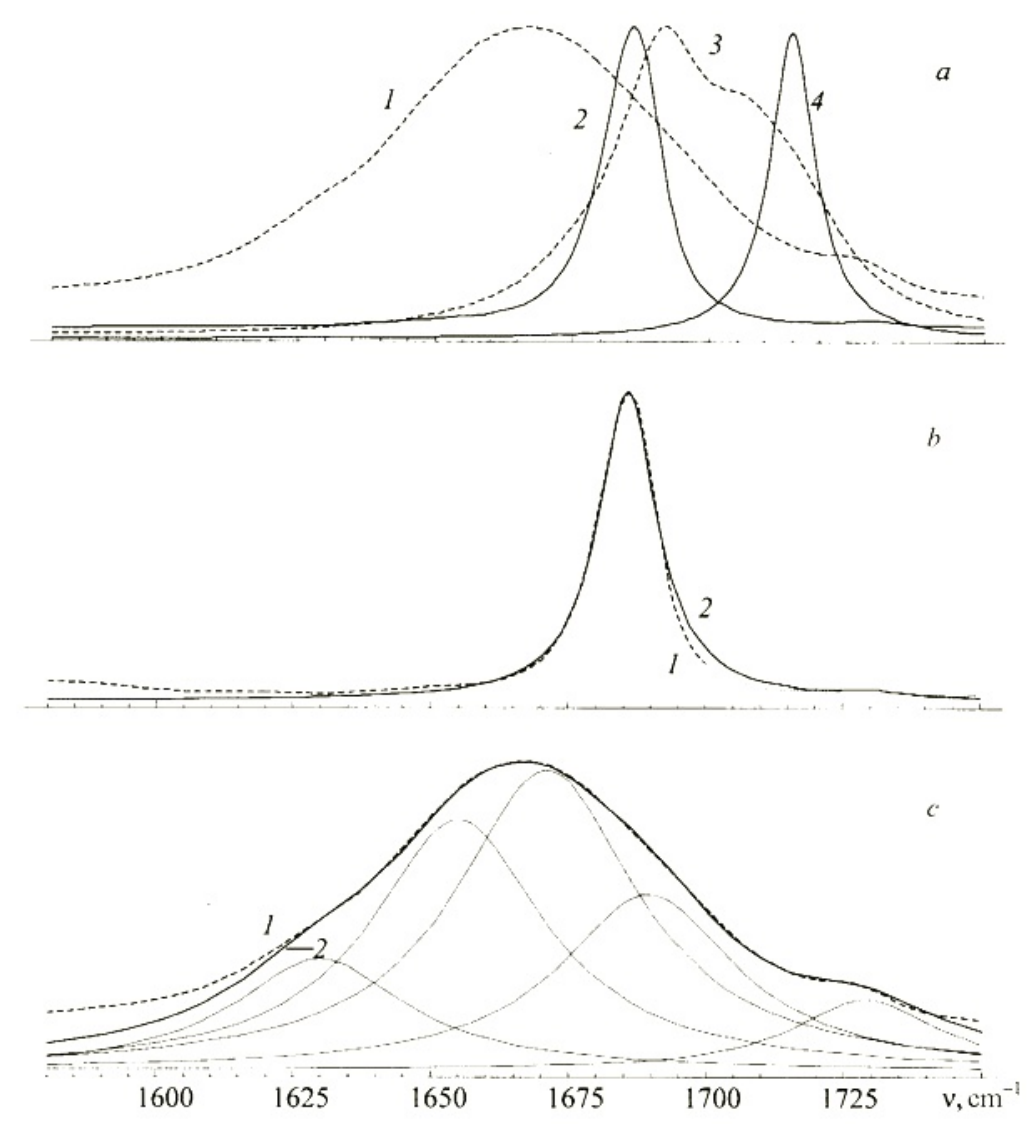

Fig. 2. Absorption band contours of $\mathrm{C}=\mathrm{O}$ stretching vibrations: pure liquid (1), $\mathrm{CCl}_{4}$ solution (2), total calculated contour for five dimers (3), calculated contour for the monomer (4) (a); experimental (1) and model (2) contours for $\mathrm{CCl}_{4}$ solution spectra (b); experimental (1) and total model (2) contours for pure liquid spectra (c).

The contour of the $\mathrm{C}=\mathrm{O}$ absorption band in pure DMF (Fig. 2a and c) could be represented as the sum of four Lorentz contours with half-widths $19.0-20.0 \mathrm{~cm}^{-1}$; centers at $1630.0,1655.0,1671.0$, and $1689.5 \mathrm{~cm}^{-1}$; and intensity ratio $0.36: 0.81: 0.97: 0.57$. Obviously the first three contours reflected vibrations of bound carbonyls; the fourth, probably free or weakly associated.

IR vibrational spectra of DMF monomer and dimers were also calculated using the B3LYP/cc-pVDZ approximation. Then the resulting force-constant matrix was partially scaled. The scaling factors were selected based on a linkage to absorption band frequencies with assignments that were assured. Such vibrations were $\mathrm{v}_{\mathrm{as}} \mathrm{CH}_{3}(2987$ and $2942 \mathrm{~cm}^{-1}$ in the vapor spectrum [3]; 2992-2998 and 2953-2960 $\mathrm{cm}^{-1}$ in liquid spectra [3, 7]), vCH $\left(2853 \mathrm{~cm}^{-1}\right.$ in the vapor spectrum [3]; 2856-2861 $\mathrm{cm}^{-1}$ in liquid spectra [3,7]), and $\mathrm{vC}=\mathrm{O}\left(1715 \mathrm{~cm}^{-1}\right.$ in the vapor spectrum [3]; 1685 [2], 1675 [3], 1659 and $1677 \mathrm{~cm}^{-1}$ [7] in liquid spectra). An analysis of the calculated DMF monomer vibrational spectrum indicated that the frequencies of methyl stretching vibrations were elevated by $\sim 100-110 \mathrm{~cm}^{-1}$; of carbonyl, by $73 \mathrm{~cm}^{-1}$. The frequencies of other stretching and also bending vibrations were elevated less significantly. The frequencies of skeletal stretching vibrations turned out to be insensitive to force-constant scaling. Thus, three scaling factors were selected. These were $\sqrt{905}$ for derivatives of energy along the $\mathrm{C}=\mathrm{O}$ bond; $\sqrt{970}$, along the aldehyde CH bond; and $\sqrt{930}$, along other bonds.

Figure 1 (spectrum 2) shows the IR spectrum of DMF monomer calculated using the B3LYP/cc-pVDZ approximation with force-field scaling. Table 3 presents the calculated frequencies and corresponding absorption band intensities compared with the experimental values. Frequencies are given in $\mathrm{cm}^{-1}$; intensities, in relative units normalized 
TABLE 3. Frequencies and Intensities in Experimental and Calculated IR Vibrational Spectra of Dimethylformamide

\begin{tabular}{|c|c|c|c|c|c|c|c|c|c|c|c|c|}
\hline \multirow{2}{*}{$\begin{array}{c}\text { Vibra- } \\
\text { tion } \\
\text { No. }\end{array}$} & \multirow[t]{2}{*}{ Assignment } & \multicolumn{2}{|c|}{$\begin{array}{l}\text { Experiment, } \\
\mathrm{CCl}_{4} \text { solution }\end{array}$} & \multicolumn{2}{|c|}{$\begin{array}{c}\text { Calculation, } \\
\text { monomer }\end{array}$} & \multicolumn{2}{|c|}{$\begin{array}{l}\text { Experiment, } \\
\text { pure liquid }\end{array}$} & \multicolumn{5}{|c|}{ Calculation (v), dimers } \\
\hline & & $v$ & $I$ & $v$ & $I$ & $v$ & $I$ & 1 & 2 & 3 & 4 & 5 \\
\hline \multirow{2}{*}{1} & \multirow{2}{*}{$v_{\mathrm{a}} \mathrm{C}^{\prime \prime} \mathrm{H}_{3}$} & \multirow{2}{*}{-} & \multirow{2}{*}{-} & \multirow{2}{*}{3053} & \multirow{2}{*}{$<0.01$} & \multirow{2}{*}{-} & \multirow{2}{*}{-} & 3056 & 3068 & 3072 & 3049 & 3052 \\
\hline & & & & & & & & 3030 & 3055 & 3043 & 3029 & 3036 \\
\hline \multirow{2}{*}{2} & \multirow{2}{*}{$v_{\mathrm{a}} \mathrm{C}^{\prime} \mathrm{H}_{3}$} & \multirow{2}{*}{2990} & \multirow{2}{*}{0.01} & \multirow{2}{*}{2999} & \multirow{2}{*}{0.04} & \multirow{2}{*}{2998} & \multirow{2}{*}{0.07} & 3004 & 2990 & 3016 & 3024 & 3018 \\
\hline & & & & & & & & 2997 & 2985 & 2994 & 2988 & 3015 \\
\hline \multirow{2}{*}{3} & \multirow{2}{*}{$\mathrm{v}_{\mathrm{a}} \mathrm{C}^{\prime \prime} \mathrm{H}_{3}$} & & & & & & & 2961 & 2966 & 2962 & 2977 & 2987 \\
\hline & & 2948 & 0.04 & 2954 & 0.01 & 2959 & 0.11 & 2954 & 2960 & 2949 & 2973 & 2981 \\
\hline & & & & & & & & 2949 & 2944 & 2948 & 2967 & 2967 \\
\hline 4 & $\mathrm{~V}_{\mathrm{a}} \mathrm{C} \quad \mathrm{H}_{3}$ & 2932 & 0.02 & 2939 & 0.12 & 2935 & 0.12 & 2944 & 2943 & 2937 & 2949 & 2959 \\
\hline & & & & & & & & 2902 & 2908 & 2896 & 2913 & 2923 \\
\hline 5 & & 2919 & 0.02 & 2902 & 0.14 & 2911 & 0.11 & 2898 & 2893 & 2892 & 2905 & 2916 \\
\hline & & & & & & & & 2891 & 2891 & 2889 & 2903 & 2905 \\
\hline 0 & $\mathrm{~V}_{\mathrm{s}} \mathrm{C} \mathrm{H}_{3}$ & 2889 & 0.01 & 2890 & 0.13 & 2885 & 0.09 & 2888 & 2881 & 2880 & 2896 & 2894 \\
\hline 7 & $v C H$ & & & & & & & 2868 & 2867 & 2824 & 2859 & 2843 \\
\hline 1 & $\mathrm{VCH}$ & 2864 & 0.01 & 2840 & 0.25 & 2865 & 0.11 & 2851 & 2811 & 2800 & 2811 & 2840 \\
\hline & $2 v_{13}$ & 2840 & 0.02 & - & - & 2846 & 0.09 & - & - & - & - & - \\
\hline & $v_{14}+v_{15}$ & 2800 & 0.02 & - & - & 2810 & 0.08 & - & - & - & - & - \\
\hline & $2 v_{15}$ & 2775 & 0.01 & - & - & 2780 & 0.05 & - & - & - & - & - \\
\hline & $v_{9}+v_{17}$ & 2758 & 0.01 & - & - & 2760 & 0.04 & - & - & - & - & - \\
\hline & $2 v_{23}$ & 1730 & 0.04 & - & - & 1729 & 0.27 & - & - & - & - & - \\
\hline & & & & & & 1689 & 0.57 & & & & & \\
\hline 8 & $v C=0$ & 1686 & 100 & 1715 & 100 & 1671 & 0.97 & 1691 & 1715 & 1715 & 1706 & 1706 \\
\hline 0 & ve & 1000 & 1.00 & 1710 & 1.00 & 1655 & 0.81 & 1659 & 1675 & 1711 & 1689 & 1692 \\
\hline & & & & & & 1630 & 0.36 & & & & & \\
\hline 0 & $\% C N$ & 1505 & $00 ?$ & 1514 & 007 & 1511 & 2020 & 1515 & 1518 & 1519 & 1516 & 1519 \\
\hline 9 & $v e N$ & 1500 & 0.02 & 1514 & 0.01 & 1511 & 0.22 & 1513 & 1512 & 1511 & 1508 & 1511 \\
\hline & $v_{19}+v_{25}$ & 1500 & 0.02 & - & - & 1502 & 0.20 & - & - & - & - & - \\
\hline 10 & $\delta_{\mathrm{a}} \mathrm{C}^{\prime} \mathrm{H}_{3}+$ & 1488 & 001 & 1477 & 003 & 1401 & 021 & 1482 & 1502 & 1493 & 1484 & 1493 \\
\hline 10 & $\delta_{\mathrm{a}} \mathrm{C}^{\prime \prime} \mathrm{H}_{3}$ & 1480 & 0.01 & $14 / 1$ & 0.03 & 1491 & 0.21 & 1481 & 1489 & 1484 & 1482 & 1484 \\
\hline 11 & $\delta_{\mathrm{a}} \mathrm{C}^{\prime} \mathrm{H}_{3}+$ & 1474 & $<001$ & 1460 & 003 & 1473 & 011 & 1477 & 1484 & 1483 & 1476 & 1474 \\
\hline 11 & $\delta_{\mathrm{a}} \mathrm{C}^{\prime \prime} \mathrm{H}_{3}$ & $14 / 4$ & $<0.01$ & 1409 & 0.03 & $14 / 3$ & 0.11 & 1474 & 1474 & 1481 & 1470 & 1473 \\
\hline 12 & $\delta_{\mathrm{a}} \mathrm{C}^{\prime} \mathrm{H}_{3}+$ & 1457 & 002 & 1455 & 003 & 1450 & 021 & 1455 & 1470 & 1471 & 1458 & 1466 \\
\hline 12 & $\delta_{\mathrm{a}} \mathrm{C}^{\prime \prime} \mathrm{H}_{3}$ & I & 0.02 & 1455 & 0.03 & 1439 & 0.21 & 1453 & 1457 & 1468 & 1452 & 1465 \\
\hline 13 & $\delta C^{\prime} \mathrm{H}_{3}$ & 1436 & 003 & 1448 & 001 & 1440 & 037 & 1446 & 1457 & 1450 & 1443 & 1450 \\
\hline 13 & $\mathrm{O}_{\mathrm{a}}<\mathrm{H}_{3}$ & 1450 & 0.05 & 1440 & 0.01 & 1440 & 0.51 & 1445 & 1449 & 1441 & 1441 & 1441 \\
\hline 14 & $\delta_{\mathrm{a}} \mathrm{C}^{\prime} \mathrm{H}_{3}+$ & 1405 & 004 & 1308 & 000 & 1411 & 025 & 1425 & 1447 & 1439 & 1431 & 1430 \\
\hline 14 & $\delta_{\mathrm{a}} \mathrm{C}^{\prime \prime} \mathrm{H}_{3}$ & 1400 & 0.04 & 1598 & 0.09 & 1411 & 0.50 & 1423 & 1440 & 1438 & 1426 & 1427 \\
\hline
\end{tabular}


TABLE 3. (Continued)

\begin{tabular}{|c|c|c|c|c|c|c|c|c|c|c|c|c|}
\hline \multirow{2}{*}{$\begin{array}{l}\text { Vibra- } \\
\text { tion } \\
\text { No. }\end{array}$} & \multirow[t]{2}{*}{ Assignment } & \multicolumn{2}{|c|}{$\begin{array}{l}\text { Experiment, } \\
\mathrm{CCl}_{4} \text { solution }\end{array}$} & \multicolumn{2}{|c|}{$\begin{array}{c}\text { Calculation, } \\
\text { monomer }\end{array}$} & \multicolumn{2}{|c|}{$\begin{array}{l}\text { Experiment, } \\
\text { pure liquid }\end{array}$} & \multicolumn{5}{|c|}{ Calculation (v), dimers } \\
\hline & & $v$ & $I$ & $v$ & $I$ & $v$ & $I$ & 1 & 2 & 3 & 4 & 5 \\
\hline \multirow{2}{*}{15} & \multirow{2}{*}{$\begin{array}{c}\delta \mathrm{NCH}+ \\
\delta \mathrm{C}^{\prime \prime} \mathrm{H}_{3}\end{array}$} & \multirow{2}{*}{1384} & \multirow{2}{*}{0.16} & \multirow{2}{*}{1387} & \multirow{2}{*}{0.10} & \multirow{2}{*}{1388} & \multirow{2}{*}{0.62} & 1405 & 1429 & 1440 & 1410 & 1423 \\
\hline & & & & & & & & 1402 & 1411 & 1426 & 1399 & 1412 \\
\hline \multirow{3}{*}{16} & \multirow{2}{*}{$\delta_{\mathrm{s}} \mathrm{C}^{\prime \prime} \mathrm{H}_{3}$} & \multirow{2}{*}{1370} & \multirow{2}{*}{ sh. } & \multirow{2}{*}{1377} & \multirow{2}{*}{0.05} & \multirow{2}{*}{1370} & \multirow{2}{*}{ sh. } & 1386 & 1395 & 1399 & 1392 & 1402 \\
\hline & & & & & & & & 1376 & 1382 & 1397 & 1386 & 1393 \\
\hline & $2 v_{24}$ & - & - & - & - & 1318 & 0.14 & - & - & - & - & - \\
\hline \multirow{4}{*}{17} & $\delta_{\mathrm{a}}\left(\mathrm{NC}^{\prime}+\right.$ & 1258 & 009 & 1255 & 008 & 1256 & 051 & 1263 & 1290 & 1261 & 1264 & 1264 \\
\hline & $\left.N C^{\prime \prime}\right)$ & 1258 & 0.09 & 1255 & 0.08 & 1250 & 0.51 & 1262 & 1284 & 1258 & 1261 & 1262 \\
\hline & $v_{23}+v_{26}$ & 1217 & 0.05 & - & - & - & - & - & - & - & - & - \\
\hline & $v_{23}+v_{27}$ & 1182 & 0.02 & - & - & 1180 & 0.16 & - & - & - & - & - \\
\hline 18 & $\rho C^{\prime} H_{3}+$ & 1150 & P0? & 1162 & 001 & 1152 & 010 & 1189 & 1266 & 1176 & 1173 & 1180 \\
\hline 18 & $\rho \mathrm{C}^{\prime \prime} \mathrm{H}_{3}$ & 1150 & 0.02 & 1102 & 0.01 & 1152 & 0.19 & 1185 & 1259 & 1165 & 1164 & 1172 \\
\hline 10 & $\rho \mathrm{C}^{\prime} \mathrm{H}_{3}+$ & 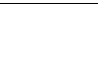 & 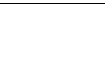 & 1111 & 5001 & 1104 & 025 & 1142 & 1130 & 1130 & 1127 & 1126 \\
\hline 19 & $\rho C^{\prime \prime} H_{3}$ & - & - & 1111 & $<0.01$ & 1104 & 0.50 & 1138 & 1128 & 1117 & 1111 & 1120 \\
\hline 20 & $\rho \mathrm{C}^{\prime} \mathrm{H}_{3}+$ & 1007 & 020 & 1076 & 023 & 1002 & 057 & 1096 & 1093 & 1094 & 1095 & 1102 \\
\hline 20 & $v \mathrm{CN}$ & 1081 & 0.20 & $10 / 6$ & 0.23 & 1092 & 0.51 & 1085 & 1092 & 1085 & 1088 & 1095 \\
\hline 21 & $\rho \mathrm{C}^{\prime} \mathrm{H}_{3}+$ & 1065 & 005 & 1052 & 004 & 1064 & 043 & 1060 & 1087 & 1084 & 1072 & 1088 \\
\hline 21 & $\rho \mathrm{C}^{\prime \prime} \mathrm{H}_{3}$ & 1003 & 0.05 & 1032 & 0.04 & 1004 & $0.4 J$ & 1057 & 1068 & 1080 & 1069 & 1084 \\
\hline & $2 v_{25}+v_{28}$ & 1033 & sh. & - & - & - & - & - & - & - & - & - \\
\hline 22 & $\gamma \mathrm{CH}$ & 1019 & $\mathrm{sh}$ & 1012 & $<001$ & 1020 & $\mathrm{sh}$ & 1053 & 1059 & 1014 & 1026 & 1013 \\
\hline 22 & $\gamma \subset \mathrm{H}$ & 1019 & sn. & 1012 & $<0.01$ & 1020 & sn. & 1050 & 1035 & 1011 & 998 & 1010 \\
\hline & $v_{24}+v_{26}$ & 1007 & sh. & - & - & - & - & - & - & - & - & - \\
\hline & $v_{24}+v_{27}$ & 978 & $<0.01$ & - & - & - & - & - & - & - & - & - \\
\hline & $2 v_{26}+v_{29}$ & 910 & $<0.01$ & - & - & - & - & - & - & - & - & - \\
\hline 23 & $v_{\mathrm{s}}\left(\mathrm{NC}^{\prime}+\right.$ & 864 & 0.04 & 862 & $<0.01$ & 865 & 0.16 & 857 & 849 & 848 & 857 & 852 \\
\hline 23 & $\mathrm{NC}^{\prime \prime}$ ) & 864 & 0.04 & 862 & $<0.01$ & 865 & 0.10 & 848 & 842 & 847 & 854 & 850 \\
\hline & $v_{26}+v_{27}$ & 669 & 0.05 & - & - & - & - & - & - & - & - & - \\
\hline 24 & $\delta \mathrm{C}=\mathrm{O}+$ & 650 & 007 & 618 & $00 ?$ & 661 & 070 & 649 & 651 & 650 & 650 & 652 \\
\hline 24 & $v_{a}\left(N C^{\prime}+N C^{\prime \prime}\right)$ & 039 & 0.01 & 040 & 0.02 & 001 & 0.10 & 646 & 647 & 649 & 648 & 650 \\
\hline & $v_{25}+v_{28}$ & 629 & 0.03 & - & - & - & - & - & - & - & - & - \\
\hline 25 & $\sigma\left(\mathrm{NC}^{\prime}+\mathrm{NC}^{\prime \prime}\right)$ & _- & - & 398 & 0.01 & 405 & - & 384 & 411 & 416 & 401 & 408 \\
\hline & O(Ne t TNe) & & & & & $400[1]$ & - & 382 & 391 & 411 & 396 & 407 \\
\hline 26 & $\gamma \mathrm{C}=\mathrm{O}$ & & & 332 & 003 & 350 & & 367 & 360 & 345 & 360 & 356 \\
\hline 26 & $\gamma=0$ & - & - & 332 & 0.03 & $350[1]$ & - & 360 & 346 & 338 & 344 & 348 \\
\hline & $\Omega C=O$ & & & & & & & 331 & 338 & 327 & 326 & 335 \\
\hline 21 & $\rho C=0$ & - & - & 310 & 0.02 & $319[7]$ & - & 238 & 336 & 318 & 322 & 331 \\
\hline & & - & - & & & & - & 323 & 323 & 289 & 261 & 304 \\
\hline 28 & $\tau \mathrm{C} \mathrm{H}_{3}+\tau \mathrm{C} \mathrm{H}_{3}$ & - & - & 241 & 0.01 & $224[7]$ & - & 320 & 292 & 276 & 253 & 298 \\
\hline
\end{tabular}


TABLE 3. (Continued)

\begin{tabular}{|c|c|c|c|c|c|c|c|c|c|c|c|c|}
\hline \multirow{2}{*}{$\begin{array}{l}\text { Vibra- } \\
\text { tion } \\
\text { No. }\end{array}$} & \multirow[t]{2}{*}{ Assignment } & \multicolumn{2}{|c|}{$\begin{array}{l}\text { Experiment, } \\
\mathrm{CCl}_{4} \text { solution }\end{array}$} & \multicolumn{2}{|c|}{$\begin{array}{c}\text { Calculation, } \\
\text { monomer }\end{array}$} & \multicolumn{2}{|c|}{$\begin{array}{l}\text { Experiment, } \\
\text { pure liquid }\end{array}$} & \multicolumn{5}{|c|}{ Calculation $(v)$, dimers } \\
\hline & & $v$ & $I$ & $v$ & $I$ & $v$ & $I$ & 1 & 2 & 3 & 4 & 5 \\
\hline \multirow{2}{*}{29} & \multirow{2}{*}{$\tau \mathrm{C}^{\prime} \mathrm{H}_{3}+\tau \mathrm{C}^{\prime \prime} \mathrm{H}_{3}$} & \multirow{2}{*}{-} & \multirow{2}{*}{-} & \multirow{2}{*}{227} & \multirow{2}{*}{$<0.01$} & \multirow{2}{*}{$215[7]$} & \multirow{2}{*}{-} & 309 & 289 & 253 & 223 & 285 \\
\hline & & & & & & & & 300 & 271 & 233 & 187 & 266 \\
\hline \multirow{8}{*}{30} & \multirow{2}{*}{$\gamma\left(\mathrm{NC}^{\prime}+\mathrm{NC}^{\prime \prime}\right)$} & \multirow{2}{*}{-} & \multirow{2}{*}{-} & \multirow{2}{*}{145} & \multirow{2}{*}{$<0.01$} & \multirow{2}{*}{$113[7]$} & \multirow{2}{*}{-} & 210 & 182 & 183 & 176 & 213 \\
\hline & & & & & & & & 205 & 178 & 160 & 129 & 205 \\
\hline & \multirow{6}{*}{$\begin{array}{l}\text { Bending } \\
\text { vibrations of } \\
\text { monomeric } \\
\text { fragments } \\
\text { relative to each } \\
\text { other in the } \\
\text { dimer }\end{array}$} & - & - & - & & & & 95 & 104 & 100 & 90 & 100 \\
\hline & & - & - & - & & & & 71 & 88 & 90 & 84 & 88 \\
\hline & & - & - & - & & & & 62 & 71 & 79 & 76 & 83 \\
\hline & & - & - & & & & & 57 & 63 & 56 & 62 & 68 \\
\hline & & - & - & & & & & 42 & 49 & 55 & 47 & 65 \\
\hline & & - & - & & & & & 29 & 28 & 38 & 31 & 57 \\
\hline
\end{tabular}

Note. $v$, stretching vibration; $\delta$, bending; $\rho$, swinging; $\gamma$, out-of-plane; $\sigma$, scissors; $\tau$, torsional; s, symmetric; a, anti-symmetric.

to the intensity of the $\mathrm{C}=\mathrm{O}$ absorption band. Complicated experimental contours were deconvoluted into simple Lorentz contours in order to determine frequencies of closely spaced bands (for example, in the regions 2700-3100, 1300-1550, and 1000-1140 $\mathrm{cm}^{-1}$ ). The calculations and literature data $[2,3,7]$ were used to assign the vibrations. It is noteworthy that two closely situated and rather strong bands at 1502 and $1500 \mathrm{~cm}^{-1}$ in the solution spectrum $(1511$ and $1502 \mathrm{~cm}^{-1}$ in the liquid spectrum) were apparently the manifestation of Fermi resonance between the principal $v C N$ stretching vibration and the combination vibration $\rho \mathrm{CH}_{3}\left(1104 \mathrm{~cm}^{-1}\right)$ and $\sigma \mathrm{CN}\left(405 \mathrm{~cm}^{-1}\right)$. The combination vibration could also be the sum of $\rho \mathrm{CH}_{3}\left(1150 \mathrm{~cm}^{-1}\right)$ and $\gamma \mathrm{C}=\mathrm{O}\left(350 \mathrm{~cm}^{-1}\right)$. However, in this instance the first version seemed more probable because the vibrations $v \mathrm{CN}, \rho \mathrm{CH}_{3}\left(1104 \mathrm{~cm}^{-1}\right)$, and $\sigma \mathrm{CN}$ had symmetry type $A^{\prime} ; \rho \mathrm{CH}_{3}$ $\left(1150 \mathrm{~cm}^{-1}\right)$ and $\gamma \mathrm{C}=\mathrm{O}, A^{\prime \prime}$, if the DMF molecule was examined in terms of a model with $C_{s}$ symmetry [7]. It is well known that the symmetries of the interacting vibrations must be the same in order for Fermi resonance to occur.

The model vibrational spectrum of the dimers shown in Fig. 1 (curve $2^{\prime}$ ) was the sum of spectra calculated for each of the five dimers. The intensities of the spectra were incorporated into the summed contour with the weights given in Table 2. Figure 2 shows portions of model spectra in the region of carbonyl stretching vibrations. The calculations indicated that stretching vibrations of aldehyde $\mathrm{CH}$ bonds in the dimers, which are involved in forming $\mathrm{H}$ bonds, were artificially elevated compared with those in the monomers. Therefore, the scaling factors $\sqrt{905}$ for derivatives of energy along the $\mathrm{C}=\mathrm{O}$ bond and bound aldehyde $\mathrm{CH}$ groups and $\sqrt{930}$, along other bonds, were used to scale the force fields of the dimers. Table 3 presents the results of the calculations.

Delocalization of vibrations occurs in most instances when dimers are formed. This is accompanied by a shift and splitting of the bands. Thus, the $\mathrm{C}=\mathrm{O}$ stretching vibration split into two components, antisymmetric (high-frequency) and symmetric (low-frequency), for dimers 1,3,4, and 5. This was due to a definite although approximate symmetry for the equilibrium configuration of these dimers. The intensity of the antisymmetric mode approximately doubled whereas that of the symmetric mode decreased by an order of magnitude compared with the intensity of the corresponding band of the monomer. The $\mathrm{C}=\mathrm{O}$ vibrations also doubled for dimer 2 , which did not have even approximate symmetry. However, they remained localized on the corresponding structural fragments and were active in the IR spectrum regardless of a slight redistribution of intensity.

Both calculated spectra (monomer and dimers, Fig. 1, spectra 2 and 2') demonstrated very convincing agreement with experimental band frequencies and intensities. 
Conclusion. The optimal geometry and characteristics of IR spectra of DMF monomer and dimers were calculated using ab initio and DFT methods and the B3LYP/cc-pVDZ approximation. It was shown that the equilibrium configuration of DMF monomer had a non-planar skeleton. Equilibrium structures of five DMF dimers were found. Their energy characteristics were determined. Vibrational bands in experimental spectra of DMF dissolved in $\mathrm{CCl}_{4}$ and of pure DMF were assigned on the basis of modeled IR spectra of the monomer and dimers. The examined dimer structures may provide a useful model of DMF structure in the condensed state because the summed spectrum of the five calculated dimeric clusters was reproduced adequately by the experimental spectrum of liquid DMF.

Acknowledgments. We are grateful to N. P. Vileishikova for help with recording the spectra.

\section{REFERENCES}

1. L. V. Vilkov, P. A. Akishin, and V. M. Presnyakova, Zh. Strukt. Khim., 3, 5-9 (1962).

2. G. Durgaprasad, D. N. Sathyanarayana, and C. C. Patel, Bull. Chem. Soc. Jpn., 44, 316-322 (1971).

3. T. C. Jao, I. Scott, and D. Steele, J. Mol. Spectrosc., 92, 1-17 (1982).

4. H. Ohtaki, S. Itoh, T. Yamaguchi, S. Ishiguro, and B. M. Rode, Bull. Chem. Soc. Jpn., 56, 3406-3409 (1983).

5. D. Steele and A. Quatermain, Spectrochim. Acta, Part A, 43, 781-789 (1987).

6. G. Schultz and I. Hargittai, J. Phys. Chem., 97, 4966-4969 (1993).

7. C. M. V. Stålhandske, J. Mink, M. Sandström, I. Pápai, and P. Johansson, Vib. Spectrosc., 14, $207-227$ (1997).

8. H. Borrmann, I. Persson, M. Sandstrom, and C. M. V. Stålhandske, J. Chem. Soc. Perkin Trans., 2, 393-402 (2000).

9. M. Malathi, R. Sabesan, and S. Krishnan, Curr. Sci., 86, 838-842 (2004).

10. X. Zhou, J. A. Krauser, D. R. Tate, A. S. Van Buren, J. A. Clark, P. R. Moody, and R. Liu, J. Phys. Chem., 100, 16,822-16,827 (1996).

11. R. Vargas, J. Garza, D. A. Dixon, and B. P. Hay, J. Am. Chem. Soc., 122, 4750-4755 (2000).

12. J. Ireta, J. Neugebauer, and M. Scheffler, J. Phys. Chem. A, 108, 5692-5698 (2004).

13. M. W. Schmidt, K. K. Baldridge, J. A. Boatz, S. T. Elbert, M. S. Gordon, J. H. Jensen, S. Koseki, N. Matsunaga, K. A. Nguyen, S. J. Su, T. L. Windus, M. Dupuis, and J. A. Montgomery, J. Comput. Chem., 14, 13471363 (1993).

14. http://www.msg.ameslab.gov/GAMESS/GAMESS.html

15. B. M. Bode and M. S. Gordon, J. Mol. Graphics Modell., 16, 133-138 (1998).

16. T. H. Dunning, Jr., J. Chem. Phys., 90, 1007-1023 (1989).

17. A. D. Becke, J. Chem. Phys., 98, 5648-5652 (1993).

18. C. Lee, W. Yang, and R. G. Parr, Phys. Rev. B: Condens. Matter Mater. Phys., 37, 785-789 (1988).

19. P. J. Stephens, F. J. Devlin, C. F. Chabalowski, and M. J. Frisch, J. Phys. Chem., 98, 11,623-11,627 (1994).

20. A. F. Jalbout, F. Nazari, and L. Turker, J. Mol. Struct. (THEOCHEM), 671, 1-21 (2004).

21. D. Xu and A. L. Cooksy, J. Mol. Struct. (THEOCHEM), 815, 119-125 (2007).

22. L. Margules, M. Carvajal, and J. Demaison, J. Mol. Spectrosc., 247, 160-166 (2008).

23. M. B. Shundalau, G. A. Pitsevich, M. A. Ksenofontov, and D. S. Umreiko, Zh. Prikl. Spektrosk., 76, No. 3, 349-357 (2009).

24. M. B. Shundalau, G. A. Pitsevich, M. A. Ksenofontov, and D. S. Umreiko, Zh. Prikl. Spektrosk., 76, No. 4, 485-492 (2009).

25. G. A. Pitsevich, M. B. Shundalau, M. A. Ksenofontov, and D. S. Umreiko, Global J. Anal. Chem., 2, in press (2011).

26. V. V. Sivchik and K. M. Grushetskii, Zh. Prikl. Spektrosk., 19, No. 2, 317-319 (1973).

27. C. C. Costain and J. M. Dowling, J. Chem. Phys., 32, 158-165 (1960).

28. E. Hirota, R. Sugisaki, C. J. Nielsen, and G. O. Sorensen, J. Mol. Spectrosc., 49, 251-267 (1974).

29. M. Kitano and K. Kuchitsu, Bull. Chem. Soc. Jpn., 47, 67-72 (1974).

30. H. Ohtaki, A. Funaki, B. M. Rode, and G. J. Reibnegger, Bull. Chem.. Soc. Jpn., 56, 2116-2121 (1983).

31. A. V. Kryvda, V. G. Gerasimov, S. F. Dyubko, E. A. Alekseev, and R. A. Motiyenko, J. Mol. Spectrosc., 254, 28-32 (2009). 
32. I. Suzuki, Bull. Chem. Soc. Jpn., 35, 540-551 (1962).

33. M. Kitano and K. Kuchitsu, Bull. Chem. Soc. Jpn., 47, 631-634 (1974).

34. Y. Kawashima, T. Usami, R. D. Suenram, G. Y. Golubiatnikov, and E. Hirota, J. Mol. Spectrosc., 263, 11-20 (2010).

35. S. Shin, A. Kurawaki, Y. Hamada, K. Shinyu, K. Ohno, A. Tohara, and M. Sato, J. Mol. Struct., 791, 30-40 (2006).

36. S. F. Boys and F. Bernardi, Mol. Phys., 19, 553-566 (1970). 